\title{
Perceptions of Preservice and Induction Physical Educators
}

\author{
Chris R. Gentry, Ph.D. \\ California State University, San Bernardino, USA \\ Julene Ensign, Ph.D. \\ Judson University, USA \\ Tom Trendowski, Ph.D. \\ University of North Carolina at Pembroke \\ Kim C. Graber, Ph.D. \\ University of Illinois at Urbana-Champaign
}

Doi: 10.19044/ejes.v5no1a1 URL:http://dx.doi.org/10.19044/ejes.v5no1a1

\begin{abstract}
This study examines the similarities and differences in perceptions of preservice and induction physical education teachers regarding their level of career preparedness and curricular preferences. Findings are based on interviews with 23 participants (12 preservice and 11 induction) from two Midwestern universities. Qualitative data from the structured interview questions designed for the study were collected and analyzed using content analysis and compared with the guiding theory. Trustworthiness for data collection and analysis was followed and validated by guidelines and recommendations (Lincoln \& Guba, 1985; Patton, 2002). In addition, 39 individuals from the two universities were surveyed regarding teacher attitudes by utilizing a validated survey (Kulinna \& Silverman, 1999). Qualitative data analysis revealed the following themes: a) Physical Education Teacher Education (PETE) programs may not adequately prepare induction teachers for the realities of the classroom environment; b) cross-curricular integrations are valued; and c) physical activity for a lifetime is a primary curricular outcome. Results suggest that PETE curriculum may need to be modified to provide increased fidelity in the induction years of physical educators. In addition, these themes signify the influence of the socialization process and its relevance to the realities of induction physical educators.
\end{abstract}

Keywords: Physical education, curriculum, teacher preparation. 


\section{Introduction}

Almost all physical educators have opinions about the content of their curriculum and the teaching methodologies that should be employed. These beliefs are strongly influenced by previous experiences, including those embedded during the $\mathrm{K}-12$ system as well as those encountered during undergraduate programs. These experiences may be beneficial or may hinder curricular choices once organizational socialization commences (Keay, 2009). When educators begin to employ philosophies instilled during physical education teacher education programs (PETE), some realize theory and practice may be vastly different. While a majority of research on physical education has focused on teaching (65\%), less than $20 \%$ has focused on curriculum (Kulinna, Scrabis-Fletcher, Kodish, \& Silverman, 2009), and to date, little research has been conducted specifically on the perception differences between preservice and induction physical educators toward preparedness, curricular outcomes, and teaching strategies. Therefore, the purpose of this study was to determine if differences existed between future and current teachers with regard to preparedness and PE curriculum.

\section{Literature Review:}

Historically, physical education curriculum has remained relatively unchanged despite the progression of interests and goals within the field. Some believe that the lack of change within the curriculum, even though curricular innovations exist, is directly related to difficulties with training physical educators (Keay, 2009). Research indicates that decisions regarding instruction and curriculum are made based on teachers' beliefs and knowledge (Bechtel \& O'Sullivan, 2007; Ennis, 1995), and change in curriculum is, therefore, linked to the instructor's expertise and the strength of that individual's convictions. These views are then, in turn, linked to a willingness to try novel approaches or persevere through the process of changing the existing circumstances. Overall, change will happen more readily in supportive environments where administrators, colleagues, and students provide a nurturing, safe environment (Bechtel \& O'Sullivan, 2007). For genuine durable change to occur, however, challenges of existing beliefs must take place. In order to begin to reconsider the values of the current physical education curriculum, learners may have to experience both the student and educator's perspectives (Timken \& McNamee, 2012). If induction teachers enter an environment where a more traditional curriculum is valued, change may be especially difficult (Keay, 2009). District policies with an emphasis on other educational priorities such as mathematics and language arts coupled with a lack of professional development opportunities are also inversely related to change in curriculum, and professional development is especially critical because a lack of exposure to new 
curricular models or instructional approaches hinders practitioner growth (Bechtel \& O'Sullivan, 2007).

In addition to the aforementioned barriers to change, the physical education environment may contain several unique challenges. First, disparity exists between the perceptions of physical educators and administrators. Most principals (59\%) feel their school's wellness policy is effective while only $35 \%$ of physical educators agree. In addition, most administrators are able to describe the changes to nutrition policies in the past few years, but many cannot describe significant changes to physical education policies (Graber, Woods, \& O’Connor, 2012). Inadequate resources, including facilities and equipment, large class sizes, lack of respect, and limited contact with students all contribute to the difficulties encountered by induction teachers (Lynn \& Woods, 2010). Research has shown even beginning teachers with strong PETE preparation can encounter difficulties in maintaining the necessary commitment to ensuring highquality PE programs (Stroot \& Whipple, 2003).

Given the considerable difficulties facing future physical educators, what continues to attract new teachers to the profession? For many, it's a love of activity and positive experiences with sports (Curtner-Smith, 2006), physical education, and physical activity in the past (Stran \& Curtner- Smith, 2009; Timken \& McNamee, 2012). Even those with previous negative experiences in physical education indicate this did not necessarily deter their subjective warrant but rather served to provide additional impetus for providing quality instruction (Keay, 2009). Overall, the process involved with becoming a teacher can be complicated. While the individual has a dynamic role in this career process, the institutions and influences of society also play critical roles (Graham, Cohn, Werner, \& Woods, 1993). Influences of former teachers and coaches as well as family members can strongly inform an individual's desire to be a physical educator (Lawson, 1983a), and just like other professions, physical education can provide a means of socialization for all within its sphere of influence (Lawson, 1988).

In most cases, those who choose this profession follow a path that moves from recruitment into the profession, through professional socialization during undergraduate training, and finally into organizational socialization as the career cycle begins (Dewar \& Lawson, 1984; Stran \& Curtner Smith, 2009; Woods \& Lynn, 2014). Each future physical educator brings a unique set of knowledge, preconceptions, and values to the field, some of which may be entirely different from the main philosophies of the group as a whole. In fact, significant contrasts in the conceptions related to teaching often exist between PETE students, student teachers, and cooperating teachers (Graham, Hohn, Werner, \& Woods, 1993). However, in order for the culture and traditions of the field to remain consistent, more 
experienced members must navigate potential differences that newcomers bring to the field (VanMaanen \& Schein, 1979). Influence, in this regard, can primarily be exerted by students, colleagues, and administrators (Lee \& Curtner-Smith, 2011). This is the process of socialization, and in the case of teacher socialization, the process is lengthy, beginning in the elementary years and continuing well into service within the profession (Keay, 20009).

\section{Occupational Socialization}

Teaching is a dynamic process, and socialization is unique to the context and individual; therefore, the theoretical framework of occupational socialization was chosen for this study because it specifically addresses how values and actions may be shaped by the complex process of socialization. The first stage of this process begins with acculturation. Taking place from early childhood until entry into preservice training, an individual gathers information about the profession through observation and interaction with parents, physical educators, and coaches (Richards \& Templin, 2011). Lortie (1975) deemed this "apprenticeship of observation" as a critical component for engendering the group's culture. By experiencing these influences firsthand, individuals develop strong beliefs, both positive and negative, regarding appropriate teaching practices and what it means to be a physical educator (Schempp \& Graber, 1992; Stroot \& Whipple, 2003). This phase may, in fact, be the most powerful of the socializing influences in physical education (Lee \& Curtner-Smith, 2011).

After acculturation, the individual enters formal teacher education training, and professional socialization begins. The dissonance which may occur between the preconceived values and beliefs acquired during acculturation and the knowledge, values, and skills espoused by the undergraduate program often leads to hard choices. During this time, preservice teachers must make decisions regarding the fidelity of existing beliefs (Schempp \& Graber, 1992). For future physical educators, PETE programs are the primary vehicle for professional socialization (Lawson, 1986), however, because physical education often requires future educators to learn certain roles (VanMaanen \& Schein, 1979), PETE programs may exert a weak socializing influence (Lee \& Curtner-Smith, 2011). To further complicate the process, professional socialization is competing against other forms of socialization, so the process itself is not automatic (Lawson, 1983a). As such, if assumptions made during the acculturation stage are not challenged, new information may not be readily used to inform future teaching practices (Timkin \& McNamee, 2012) and this, in turn, influences the quality of physical education programs (Xiang, Lowy, \& McBride, 2002). 
Upon completion of professional training, a third type of socialization, organizational socialization, occurs as the individual enters the field. Learning the responsibilities, culture, and roles that exist within physical education swiftly takes place in the working environment. Organizational socialization, a crucial component of professional development (Laker \& Jones, 1998), may help solidify the practices and values adopted during PETE programming (Lawson, 1983a), or if the value systems of the organization and individual are different a wash-out effect may occur as the new physical educator encounters the reality of the profession (Richards \& Templin, 2011). The latter is especially true when the physical educator is hired into a large, bureaucratic organization (Lawson, 1986). If a PETE preparation program is inadequate or the new teacher faces the process alone, the results of organizational socialization can be extremely powerful (Lawson,1983b). If the assumptions made during the acculturation stage are not challenged new information may not be readily used to inform teaching practices (Timkin \& McNamee, 2012) and this, in turn, influences the quality of physical education programs (Xiang, Lowy, $\&$ McBride, 2002). Furthermore, the unique language, shared experiences, etiquette, and customs of the culture all serve to exert influence on beginning teachers (VanMaanen \& Schein, 1979) and serve as a vehicle for passing beliefs and protocols on to the next generation (Lee \& Curtner-Smith, 2011).

Encompassing all of these aforementioned types of socialization, acculturation, professional socialization, and organizational socialization, is the broader concept of occupational socialization (Dewar \& Lawson, 1984; Stran \& Curtner Smith, 2009). This overarching concept denotes all the influences that initially draw a person to the profession as well as those that are later responsible for the actions of the individual employed in the field (Lawson, 1986). Central to the concept of occupational socialization is the premise that many different forms of socialization may have overlapping, competing influences (Lawson, 1986). The power of this process is clearly evident when beginning teachers do not demonstrate fidelity to the knowledge and information regarding best practices learned during PETE (Lawson, 1986).

As preservice teachers begin to enter the profession, new responsibilities and challenges are encountered, and these individuals begin to establish their own professional place in the school's culture (Herbert \& Worthy, 2001). Often, unrealistic expectations are created during the preservice years, and the difficulties encountered in the day-to-day work of teaching are substantial (Herbert \& Worthy, 2001). In addition, entry into the physical education profession may be more difficult in cultures where marginalization and isolation exist (Richards \& Templin, 2011). All of these factors may serve to accentuate potential differences in values 
between those instilled during PETE programs and those espoused during the induction years. To this end, the primary research question was as follows:

What are the similarities and contrasts between the perceptions of preservice PETE students and induction K-12 physical educators regarding teacher preparedness and curricular outcomes?

\section{Methods:}

\section{Participants \& Settings}

Participants for the study were selected from two Midwestern universities. The first university, State, is a large, public, research institution with a Carnegie Classification of Doctoral Universities: Highest Research Activity and a student enrollment of over 45,000 . The second, Private, is a small, private, liberal-arts institution with a Carnegie Classification of Master's Colleges and Universities: Small Programs and an enrollment of approximately 1000 (Carnegie Foundation, 2017). Both universities offer PETE programs similar in curricular nature due to existing state standards and requirements.

The criteria for inclusion as a preservice teacher included enrollment in a PETE program and a current student teaching placement or placement within the next semester. The criteria for inclusion as an induction teacher included a K-12 PE certification as well as current employment as a first- or second-year physical educator. The classifications for preservice and induction teachers follow the model outlined by Fessler and Christensen (1992). Entry into each environment to recruit participants was secured only after receiving Institutional Review Board approval. Each institution provided a database containing contact information for preservice students as well as recent graduates. Initial contact during recruitment was secured through email, and willingness to participate was documented. Each participant was given a copy of the informed consent, including a full description of the study including risks and rewards.

\section{Instruments}

After obtaining consent, each recruit participated in one formal, semi-structured interview lasting approximately 45 minutes. In total, 11 (6 State +5 Private) induction teachers and 12 ( 6 State +6 Private) preservice teachers were interviewed. Interview guide questions were written to ask the same questions to both groups (preservice and induction) but adjustments in wording were made to cater the questions to the audience. Induction teachers were asked 13 questions, compared to 10 for preservice teachers, to gather additional information on their curriculums and perceptions of preparedness. To further ensure continuity and decrease 
variation, all questions were prepared in advance, and during each interview, the questions were asked in a uniform order and manner (Patton, 2002). In some cases, additional follow- up questions were asked to further facilitate data collection. Questions in both interview guides focused on goals for physical education, teaching strategies, and factors influencing change in PE curriculum. In order to prevent bias, all participants were interviewed by individuals on the research team with whom they had no previous interaction. Each interview was audio recorded and later transcribed.

In conjunction with interviews, an online survey, validated by Kulinna and Silverman (1999), was employed to gather demographic information with Likert-type responses to questions regarding teachers' attitudes toward curriculum in physical education. This instrument was disseminated to a pool of 60 potential participants from the aforementioned university databases, including those participants previously interviewed. In all, 39 individuals completed the survey, including 25 preservice and 14 induction teachers. All preservice participants had no formal teaching experience and were engaged in the last year of PETE training. Induction respondents, 12 primary and 2 secondary full-time physical educators, had a mean of 1.09 years of experience. Participants' self-identified race and ethnicity was predominantly Caucasian (78\%) followed by Hispanic (11\%), African-American (5\%), Asian-American (3\%), and Pacific Islander (3\%). Survey questions, 36 total, focused on the following domains: a) physical activity and fitness; b) individual development; c) motor skill development; and d) social development. Respondents rated their beliefs regarding questions in each domain with the following scale: 1 = extremely important, 2 = very important, 3 = somewhat important, $4=$ not very important, and $5=$ not important. Willingness to answer survey questions signified each individual's desire to participate, and an IRB approval for a waiver of documentation of consent was obtained prior to data collection for the survey. Similar to the interview process, pseudonyms were assigned for all survey participants.

\section{Data Analysis}

Interview data were analyzed using Huberman and Miles' process (1994). The process started with data collection, and during this stage initial themes were recorded. Second, data reduction included further coding into themes and reduction of irrelevant data. Third, data display entailed organizing the themes into categories and visual displays to further examine the data. Finally, data and themes were compared to the guiding theory (Huberman \& Miles, 1994).

Survey data were analyzed using SPSS 22. Demographic information and descriptive statistics were used to triangulate interview findings related 
to curricular preferences. To do this, groups were divided by domains and population (Private College preservice teachers, State University preservice teachers, Private College induction teachers, and State University induction teachers). Finally, comparisons were made between preservice and induction teachers without separating programs.

\section{Trustworthiness}

In order to enhance trustworthiness, multiple methods consistent with techniques outlined by Lincoln and Guba (1985) were employed during this study, including: a) an audit trail; b) member checking; c) cross-checking for negative cases; d) investigator triangulation; e) data source triangulation; and f) use of participants' quotes. An audit trail was created to specifically document the methodology used to conduct this study. Documents in the audit trail included all raw interview data, transcripts, coded documents, and the contact database. Member checking was used to verify accuracy of data gathered during interviews (Patton, 2002). Transcriptions were supplied to each participant to confirm the quality of the documents. Cross-checking for negative cases occurred during data analysis, and the researchers working as a team continued to discuss results and themes throughout the process. Finally, direct quotes were used as another means to accurately portray the views of the participants.

\section{Results:}

Themes and subthemes emerged during the analysis of each group (Private preservice, State preservice, Private induction, and State induction) regarding the role of PETE in teacher preparadeness, lifetime physical activity, and other subject areas (math, English, etc.) in curriculum preparation. The themes of both preservice groups were then compared to those of the induction groups to provide additional information. In total, three predominant themes were identified regarding classroom management, cross-curricular activities, and curricular outcomes.

\section{Theme 1: Physical Education Teacher Education (PETE) programs may not adequately prepare induction teachers for the realities of the classroom environment.}

The majority of preservice and induction teachers expressed that their knowledge, skills, values, and sensitivities during curriculum development were influenced by their respective PETE programs. Timothy, a Private University preservice teacher, summarized the sentiments of the group when he described his level of preparation with the following words: "It would definitely have to be just from taking classes at school and from my professors at school. They've all done a really good job in teaching me close to 
everything that I know right now." Yet, despite statements to this effect, when induction teachers were questioned about ways they were prepared to deal with classroom challenges in physical education, only two induction teachers mentioned their PETE program and professors as a primary source of preparation. In contrast, several mentioned that their university did not adequately prepare them for the realities of teaching. Mr. Zigg, a State University induction teacher, noted that "there was no class at (State) that prepared me for anything of that management that I had to deal with [in my job]."

In terms of challenges, classroom management was mentioned as an area of frustration by many of the induction teachers during interviews and identified as an important aspect of effective teaching during the survey. In fact, despite their vast differences in Carnegie classification, students and induction teachers from both universities believed that classroom management was one of the biggest challenges facing induction teachers. Ms. Rolf, a Private University induction teacher, stated, "It doesn't matter how many times you go over the safety in a setting like a classroom. I was not prepared for all the issues that I would have with the kids the first semester." Survey data revealed that both induction teachers and preservice teachers believe an important characteristic of a physically-educated person is responsible personal and social behavior during physical activity. This was indicated by a mean response of $1.7(S D=0.6)$. In addition, 34 of 39 participants rated this characteristic as either extremely important or very important. To that point, Mr. Renfro, a State University induction teacher, expressed during an interview that classroom management should be an emphasis of PETE. In the end, even though most indicated that they valued the content taught in their respective PETE programs, the lack of experience with classroom management seemed to have the largest overall impact on the perceptions of the group.

\section{Theme 2: Cross-curricular integrations are valued.}

A majority of the preservice and induction teachers believed that other school subjects and teachers play a critical role in the curricular choices within physical education. Many of the students and teachers felt it was important to include cross-curricular activities within the curriculum, although their reasons for doing so varied.

To start, several students and teachers mentioned that physical education should incorporate activities that include curricular content from other core subjects. Marty, a State University preservice teacher explained his intentions with the following words: "I would like to be able to incorporate what students are learning in other classes into PE. I'm not doing it right now, but when I become a teacher, I would envision myself communicating a lot 
with other teachers in the school and trying to incorporate different units in math and science and all those classes and incorporate it into PE." Similarly, Winston, a Private University preservice teacher, stated that he "would like to incorporate other subjects into PE."

In addition, the need for increased collaboration between physical educators and other teachers to promote each other's content area was also expressed during interviews. Some stated that they saw this as a way to reinforce multiple subject curriculums at the same time. Bill, a State University preservice teacher, felt that some natural integrations existed, especially between mathematics and physical education. Ms. Peters, a Private University induction teacher, understood the importance of "constant communication" in that process and the mutual learning it could provide for both students and teachers.

\section{Theme 3: Physical activity for a lifetime is a primary curricular outcome.}

Along with skill development and enjoyment of physical activity, a recurring theme within both populations was the concept of promoting physical activity for a lifetime. It was a persistent response during questions regarding both the purpose and outcomes of PE. Carol, a Private University preservice teacher, stated, 'Physical activity isn't just something that should be taking place in school, but it needs to be something that you're building on for a lifetime." Similarly, Karen, a State University preservice teacher, felt that physical education "should be a place where students can learn different ways of staying healthy that they're able to use outside of the classroom outside the school...so they'll feel comfortable once they leave the school to continue working out and staying healthy", and Ms. Azaro, a State University induction teacher, summarized the sentiments of the group with the following words:

"I want kids to walk away with... knowing that physical activity is vital to life. I just really want them to take things we learn and just apply them to real life. 'Cause they're only in school for so long, and so, I think that as a teacher you're supposed to try and mold them, so they can go out and do things on their own."

Survey data regarding this theme substantiate the qualitative interview results. In responding to physical education goals and programmatic foci, the vast majority, $90 \%$ of participants, rated developing components of healthrelated fitness and promoting the development of motor skills for the participation in a variety of sport activities as either very important or extremely important. While these results indicate consensus within the overall group, contrasting emphases between preservice and induction groups were noted. In working toward achieving the end result, preservice teachers most readily identified a need for students to develop aspects of personal growth, 
such as an increased self-concept, while induction teachers emphasized competency in developing physical skills, such as those related to healthrelated fitness and motor skill proficiency.

In addition, the overwhelming majority of participants, $95 \%$ and $87 \%$, rated promoting regular physical activity habits and developing health benefits from participation in physical activities as either very important or extremely important, respectively. The latter, healthy benefits, was especially emphasized among the responses of preservice teachers. Enjoyment during participation was also important to survey respondents. All groups rated this category highest when selecting the traits of a physically-educated person, and overall, $90 \%$ identified this characteristic as either very important or extremely important.

\section{Discussion:}

This study was designed to compare and contrast perceptions of preparedness, curriculum outcomes, and teaching strategies among preservice and induction teachers. The first theme revealed during data collection indicated the importance both groups placed on adequate PETE preparation. Both preservice and induction teachers believed that classroom management was a major issue facing physical educators. In fact, focusing on classroom management issues may result in decreased time spent in physical activity, and it has been postulated that teachers over time decrease their standards for physical education because students' motivation and behavior are low (Ennis, 1995). Additionally, the concerns preservice teachers have regarding management and discipline issues remain persistent despite attempts to refocus attention on students (Woods, Goc Karp, \& Escamilla, 2000). Over time, chronic issues with student behavior may lead to wash-out, a period of time when the influence of the professional program decreases (Zeichner \& Tabachnick, 1981). Factors inducing wash-out include lack of facilities, lack of prestige and respect, the devaluing subculture of other teachers, and desire for acceptance (Blankenship \& Coleman, 2009). In this study specifically, teachers faced wash-out inducing factors such as lack of physical gym space, large class sizes, lack of equipment, and the added pressure of student behavior issues. These contextual factors hinder progress in physical education (Goodlad, Soder, \& Sirotnik, 1990) (Griffen, 1985) and serve to create an "institutional press" where new ideas and practices are disregarded (Zeichner \& Tabachnik, 1981).

Additionally, induction teachers stated that their PETE programs shaped their knowledge, skills, values and sensitivities; however, as these same teachers navigated challenges inside and outside the classroom, the strategies they utilized were often not derivatives of their professional socialization but rather part of their organizational socialization. In other 
words, strategies embedded during pre-service teaching may not be utilized, especially if they do not seem applicable to real world situations. This disconnect may be addressed by focusing PETE programs on best practices and innovative strategies, rather than on traditional methods which reinforce rather than challenge the status quo (Timken \& McNamee, 2012). PETE programs should take steps to ensure that individuals are equipped with the necessary strategies to deal with challenging occupational socialization issues (Lux \& McCullick, 2011; Richards, Templin, \& Gaudreault, 2013). Successful PETE outcomes should prepare induction teachers to navigate these adverse conditions and decrease reality shock, the difference between ideals modeled during teacher training and the reality of day-to-day experiences in the classroom (Veeman, 1984).

More authentic field experience and classroom discussions about problematic issues that teachers may face will decrease reality shock and, perhaps, increase the effectiveness of professional socialization. Early field experiences may directly help teachers navigate behavioral management issues and provide positive influences on the development of preservice efficacy levels and teaching skills by providing opportunities to gain experience through observation, simulation, tutoring, and small group instruction (Clift \& Brady, 2005). Additionally, in order for recent graduates to utilize sound pedagogy and focus on the curricula prescribed by quality PETE programs, it may be beneficial to provide intentional avenues where preservice students can practice implementing managerial skills relevant to newly-hired physical educators, better informing their focus on curriculum content in the field while limiting the potential for wash-out and reality shock.

With the second theme, the value of cross-curricular integrations, it is important to note the current emphasis placed on this concept for both preservice and induction teachers. Unlike the previous theme, this is one PETE value that remains consistent, even in the early years of teaching. Cross-curricular knowledge has been shown to increase literacy (Mears, 2003) as well as increase participation and enjoyment of physical education (Stivaktaki, Mountakis, \& Bournelli, 2010). While integration of classroom content into the P.E. curriculum is definitely beneficial for students, it does require intentionality on the part of the physical educator. A desire to build relationships with other classroom teachers as well having access to the time and resources required to adapt activities would be crucial components of this process. Because the instructional behaviors of teachers and learning outcomes for students are influenced by pre-existing beliefs (Xiang, Lowy, $\&$ McBride, 2002), emphasis on cross-curricular integration of content into P.E. will continue to be an extremely important component of PETE curricula. Additionally, students can benefit from both observing and 
providing samples of content integration strategies in controlled, clinical environments.

For the last theme, interview and survey questions indicated an emphasis on developing skills and teaching strategies to aid students in acquiring the skills necessary to stay active throughout life. Congruently, as cited in the literature, the main goal of physical education is to prepare youth for a lifetime of physical activity and provide them with physical activity during physical education classes (Sallis et al., 2012). Similarly, Biddle, Gorely, and Stensel (2004) state that it is "established beyond any reasonable doubt, and widely accepted across societies, that regular participation in physical activity is an essential component of a healthy lifestyle" (p.683). Links between physical inactivity and chronic disease abound in the research, and the media continues to provide coverage of the issue with high profile intervention strategies such as the National Football League's "Fuel Up to Play 60" campaign (Fuel Up to Play 60, 2017). With obesity rates for children ages 6-11 nearing $20 \%$, this issue is likely to remain a strong influence in P.E. curriculums in the future (Centers for Disease Control, 2013).

In working toward that end, the results suggest a shift between preservice to induction. Induction teachers felt compelled to focus on helping students develop skills in the psychomotor domain rather than the affective domain as identified by the majority of preservice participants. This dissonance demonstrates an altering of perception between preservice training and induction status, with induction teachers shifting their focus from intrapersonal skills to creating students who can readily apply lifespan fitness skills. The largest barrier for the implementation of the goals within this theme, as identified by interview data, may simply be developing expertise in learning how to incorporate the concept of lifetime physical activity in the curriculum. This also corroborates the results within the first theme whereby participants felt underprepared for some aspects of induction.

\section{Implications:}

Based on analysis, two major implications emerged due to the findings of this study. First, this study suggests a disconnect between PETE pedagogy and the required managerial knowledge necessary for beginning teachers. Perceptions of important curriculum content among induction teachers may not be thoroughly addressed through PETE programming. Teaching philosophies and value orientations such as instilling lifespan physical activity, using cross-curricular integrations, and providing appropriate vehicles for student choice were strongly evident in this research, but PETE programs need to provide the knowledge necessary to bridge the gap between what preservice teachers learn and what induction teachers need. It has been noted that "knowing about" a particular curricular approach is not the same as 
"knowing how" to use that knowledge in practice (McMahon \& MacPhail, 2007). Implementation of early, authentic field experiences may aid the application process.

Second, even graduates from high-quality PETE programs find contextual factors in the field can and do limit curricular choices. The physical environment of the school significantly impacts not only the quality of physical education, but also the quantity of physical education (Chow, McKenzie, \& Louie, 2009). For example, a physical educator with a strong belief in cross-curricular activities may be limited in the amount of content integration by a lack of space, equipment, or even student behavior. PETE programs must provide a more realistic representation of the working environment along with practical strategies for mediating barriers faced by induction teachers. In addition, it may be necessary for PETE programs need to ensure that cross-curricular efforts do not limit our state and national physical education standards.

\section{Limitations:}

Overall, this research did not have the capacity to address the extent to which induction teachers applied theoretical knowledge gained from their PETE programs. In addition, this research only uncovered themes for a specific population during a finite data collection period. While results from this study may not be generalizable to all populations, it is our hope that this research can be utilized to spark discussion among PETE faculty and students. Future research, with a longitudinal approach, should focus on changes in teaching philosophy and perceptions throughout the entire career cycle in order to understand how a shift in career stages might impact the perceptions of individuals from the same PETE program (Woods \& Lynn, 2001). Data collected from a larger population across a diverse variety of institutions may substantiate the overall significance of subsequent studies.

\section{References:}

Bechtel, P., \& O'Sullivan, M. (2007). Enhancers and inhibitors of teacher change among secondary physical educators. Journal of Teaching in Physical Education, 26, 221-235.

Blankenship, B., \& Coleman, M. (2009). An examination of "wash-out" and workplace conditions of beginning physical education teachers. Physical Educator, 66, 97-111.

Biddle, S., Gorely, T., \& Stensel, D. (2004). Health-enhancing physical activity and sedentary behaviour in children and adolescents. Journal of Sports Sciences, 22, 679- 701.

Carnegie Classification of Institutions of Higher Education. (2017). About Carnegie Classification. 
Retrieved from http://carnegieclassifications.iu.edu/.

Centers for Disease Control and Prevention. (2013). Childhood overweight and obesity. Retrieved

from

http://www.cdc.gov/obesity/childhood/index.html.

Chow, B., McKenzie, T.., \& Louie, L. (2009). Physical activity and environmental influences during secondary school physical education. Journal of Teaching in Physical Education, 28, 21-37.

Clift, R., \& Brady, P. (2005). Research on methods courses and field experiences. In M. Cochran-Smith, M. \& K. Zeichner (Eds.) (2005). Studying teacher education: The report of the AERA panel on research and teacher education (pp. 309-424). Location: New York, NY: Routledge.

Curtner-Smith, M. (2006). Influence of biography, teacher education, and entry into the workforce on the perspectives of first-year elementary school physical education teachers. European Journal of Physical Education, 3, 7598.

Dewar, A., \& Lawson, H. (1984). The subjective warrant and recruitment into physical education, Quest, 36, 15-25.

Ennis, C. (1995). Teachers' responses to noncompliant students: The realities and consequences of a negotiated curriculum. Teaching and Teacher Education, 11, 445-460.

Fessler, R., \& Christensen, J. (1992). The teacher career cycle: Understanding and guiding the professional development of teachers. Needham Heights, MA: Allyn and Bacon.

Goodlad, J., Sider, R., \& Sirotik, K. (Eds.) (1990). The moral dimensions of teaching. San Francisco: Jossey-Bass. Griffin, P. (1985). Teaching in urban multiracial junior high school physical education program: The power of context. Quest, 37, 154-165.

Graber, K., Woods, A., \& O'Connor, J. (2012). Impact of wellness legislation on comprehensive school health programs. Journal of Teaching in Physical Education, 31, 163-181.

Graham, K., Hohn, R., Werner, P., \& Woods, A. (1993). Prospective PETE students, PETE student teachers, and clinical model teachers in a university teacher education program. Journal of Teaching in Physical Education, 12, 161-179.

Hebert, E., \& Worthy, T. (2001). Does the first year of teaching have to be a bad one? A case study of success. Teaching and Teacher Education, 17, 897911.

Huberman, A., \& Miles, M. (1994). Qualitative data analysis. Thousand Oaks, CA: Sage.

Keay, J. (2009). Being influenced or being an influence: New teachers' induction experiences.

European Physical Education Review, 15, 225-247. 
Kulinna, P., Scrabis-Fletcher, K., Kodish, S., Phillips, S., \& Silverman, S. (2009). A decade of research literature in physical education pedagogy. Journal of Teaching in Physical Education, 28, 119-140.

Kulinna, P., \& Silverman, S. (1999). The development and validation of scores on a measure of teachers' attitudes toward teaching physical activity and fitness. Educational and Psychological Measurement, 59, 507-517.

Laker, A., \& Jones, K. (1998). A longitudinal study of evolving student teacher concerns: Baseline report. European Journal of Physical Education, 3, 200-211. Lawson, H. (1983a). Toward a model of teacher socialization in physical education: The subjective warrant, recruitment, and teacher education. Journal of Teaching in Physical Education, 2, 3-16.

Lawson, H. (1983b). Toward a model of teacher socialization in physical education: Entry into schools, teachers' role orientations, and longevity in teaching (part 2). Journal of Teaching in Physical Education, 3, 3-15.

Lawson, H. (1986). Occupational socialization and the design of teacher education programs.

Journal of Teaching in Physical Education, 5, 107-116.

Lawson, H. (1988). Occupational socialization, cultural studies, and the physical education curriculum. Journal of Teaching in Physical Education, 7, 265-288.

Lee, H., \& Curtner-Smith, M. (2011). Impact of occupational socialization on the perspectives and practices of sport pedagogy doctoral students. Journal of Teaching in Physical Education, 30, 296-313.

Lincoln,Y., \& Guba, E. (1985). Naturalistic inquiry. Beverly Hills, CA: Sage. Lortie, D. (1975). Schoolteacher: A sociological study. Chicago, IL: University of Chicago Press.

Lynn, S., \& Woods, A. (2010). Following the yellow brick road: A teacher's journey along the proverbial career path. Journal of Teaching in Physical Education, 29, 54-71.

Lux, K., \& McCullick, B. (2011). How one exceptional teacher navigated her working environment as the teacher of a marginal subject. Journal of Teaching in Physical Education, 30, 358-374.

Mears, B. (2003). The effects of combined reading and physical education skill instruction on the development of locomotor and reading skills. Missouri Journal of Health, Physical Education, Recreation and Dance, 13, 1-13.

McMahon, E., \& MacPhail, A. (2007). Learning to teach sport education: The experiences of a pre-service teacher. European Physical Education Review, 13, 229-249.

National Dairy Council. (2017). Fuel Up to Play 60. Retrieved from https://www.fueluptoplay60.com/

Patton, M. (2014). Qualitative research and evaluation methods (4th ed.). Thousand Oaks, CA: Sage. 
Richards, K., \& Templin, T. (2011). The influence of a state mandated induction assistance program on the socialization of a beginning physical education teacher. Journal of Teaching in Physical Education, 30, 340-357.

Richards, K., Templin, T., \& Gaudreault, K. (2013). Understanding the realities of school life: Recommendations for the preparation of physical education teachers. Quest, 65, 442-457.

Sallis, J., McKenzie, T., Beets, M., Beighle, A., Erwin, H., \& Lee, S. (2012). Physical education's role in public health: Steps forward and backward over 20 years and hope for the future. Research Quarterly for Exercise and Sport, 83, 125-135.

Schempp, P., \& Graber, K. (1992). Teacher socialization from a dialectical perspective: Pretraining through induction. Journal of Teaching in Physical Education, 11, 329-348.

Stivaktaki, C., Mountakis, C., \& Bournelli, P. (2010). The effect of a crosscurricular study programme in physical education on the attitudes and perceptions of Greek children towards traditional (folk) dance in the first year of secondary school. Research In Dance Education, 11(3), 193-211.

Stran, M., \& Curtner-Smith, M. (2009). Influence of occupational socialization on two preservice teachers' interpretation and delivery of the sport education model. Journal of Teaching in Physical Education, 28, 38-53.

Stroot, S., \& Whipple, C. (2003). Organizational socialization: Factors effecting beginning teachers. In S. Silverman \& C. Ennis (Eds.), Student learning in physical education: Applying research to enhance instruction, pp. 275-294). Champaign, IL: Human Kinetics.

Timken, G., \& McNamee, J. (2012). New perspectives for teaching physical education: Preservice teachers' reflections on outdoor and adventure education. Journal of Teaching in Physical Education, 31, 21-38.

United States Department of Health and Human Services. (2013). Let's move. Retrieved from http://www.letsmove.gov

VanMaanen, J., \& Schein, E. (1979). Toward a theory of organizational socialization. In B. Staw, (Ed.), Research in organizational behaviour (pp. 209261).Greenwich, CT: JAI Press.

Veenman, S. (1984). Perceived problems of beginning teachers. Review of Educational Research, 54, 143-178.

Williams, J., \& Williamson, K. (1998). The socialization strategies for first year physical education teachers: Conflict and concessions. Physical Educator, 55, 78-88.

Woods, A., \& Lynn, S. (2001). Through the Years: A longitudinal study of physical education teachers from a research-based preparation program. Research Quarterly for Exercise and Sport, 72, 219-231. 
Woods, A., \& Lynn, S., (2014). One physical educator's career cycle: Strong start, great run, approaching finish. Research Quarterly for Exercise and Sport, 85, 68-80.

Woods, M., Goc Karp, G., \& Escamilla, E. (2000). Preservice teachers learning about students and the teaching-learning process. Journal of Teaching in Physical Education, 20,15-39.

Xiang, P., Lowy, S., \& McBride, R. (2002). The Impact of a field-based elementary physical education methods course on preservice classroom teachers' beliefs. Journal of Teaching in Physical Education, 21, 145-161.

Zeichner, K., \& Tabachnik, N. (1981). Are the effects of university teacher education "washed out" by school practice? Journal of Teacher Education, 32, 7-11. 